\title{
Effects of nonylphenol on cholinesterase and carboxylesterase activities in male guppies (Poecilia reticulata)
}

\author{
Mei-Hui Li* \\ Environmental Toxicology Laboratory, Department of Geography, National Taiwan University, 1, Section 4, Roosevelt Road, Taipei 106, Taiwan
}

\section{A R T I C L E I N F O}

\section{Article history:}

Received 7 August 2007

Received in revised form

23 January 2008

Accepted 23 February 2008

Available online 18 April 2008

Keywords:

Guppy

Nonylphenol

Cholinesterase

Carboxylesterases

\begin{abstract}
A B S T R A C T
Compared to the estrogenic effects of 4-nonylphenol (NP), there is little data available on other potential toxic effects of NP in aquatic animals. The effects of NP on cholinesterase (ChE) and carboxylesterase (CbE) activities of male guppies exposed to $10,60,150$, or $300 \mu \mathrm{g} \mathrm{L}^{-1} \mathrm{NP}$ were examined after $1,2,4$, and 7 days of treatment. A significant muscle ChE inhibition, that used acetylthiocholine iodide as a substrate, was noted in male guppies in all NP treatment groups after a 4-day exposure, and 60 and $150 \mu \mathrm{g} \mathrm{L}^{-1}$ of NP treatment groups after a 7-day exposure. All guppies exposed to $300 \mu \mathrm{g} \mathrm{L}^{-1} \mathrm{NP}$ died during the 7-day treatment. However, there was no significant inhibition of muscle ChE that used butyrylthiocholine iodide as a substrate in male guppies for any NP treatments in different exposure times. There were no CbE activity differences in livers of male guppies among NP treatment groups after different exposure times. This is the first report showing the ChE activity inhibition by NP in fish. Further mechanistic studies are needed to define how NP directly or indirectly alters ChE activities at molecular level. The implication of ChE inhibition of NP on potential impacts of aquatic animals also warrants further research.
\end{abstract}

(c) 2008 Elsevier Inc. All rights reserved.

\section{Introduction}

4-Nonylphenol (NP) has been widely used in many industrial applications as well as household cleaning products. It has been found worldwide in wastewater discharges, sewage-treatmentplant effluents, natural water, and sediments (Bennie, 1999; Ying et al., 2002). NP is a ubiquitous, persistent, and easily bioaccumulated pollutant (Ying et al., 2002), and its potential effects are found in many aquatic animals both acutely and chronically (Nimrod and Benson, 1996; Lussier et al., 2000; Staples et al., 2004). In the past, most published studies have mainly focused on the estrogenic effects of NP as an endocrine disruptor both in vivo and in vitro (Nimrod and Benson, 1996; Bandiera, 2006). Compared to the estrogenic effects of NP, there is little data available on other potential toxic effects of NP in aquatic animals.

In fact, NP may have damaging effects on important physiological processes without involvement of estrogen receptors (Khan et al., 2003). For example, acetylcholinesterase (AChE) activity of rat pheochromocytoma PC12 cells incubated with NP for $24 \mathrm{~h}$ was found to be significantly inhibited (Talorete et al., 2001). In general, the immediate result of $\mathrm{AChE}$ inhibition will cause an increase in acetylcholine that may result in a decrease in

\footnotetext{
* Fax: +886223622911.

E-mail address: meihuili@ntu.edu.tw
}

cholinergic receptor number, which is a compensatory response to an acetylcholine buildup. Interestingly, Jones et al. (1998) did report that NP exposure could cause a decrease in brain muscarinic cholinergic receptors in three species of trout in vitro. However, there is little information on effects of NP on ChE activities of aquatic animals in vivo. Lee and Choi (2006) reported that there was no significant difference in the AChE activities of Chironomus riparius larva after $24 \mathrm{~h}$ of NP exposure between 10 and $100 \mu \mathrm{g} \mathrm{L}^{-1}$. On the other hand, Li (2008) found a significant decrease in the ChE activities of planarian exposed to NP at $500 \mu \mathrm{g} \mathrm{L}^{-1}$ after $48 \mathrm{~h}$ treatment. Considering the important role of ChE in animal's behavior and physiology (Soreq and Seidman, 2001), the effects of ChE inhibition by NP in aquatic vertebrates are still scarce and warrant further research.

The guppy has long been used as a popular animal model in ecological and evolutionary research as well as in behavioral studies. Recently, it is also widely applied as a test organism both in situ and laboratory bioassays, because it is a readily available and easily handled small body-sized species with a short life cycle (Castro et al., 2004; Araújo et al., 2006). In addition, several studies combining various biochemical measurements in guppies were very useful for studying environmental pollution problems (Pierson, 1981; Frasco and Guilhermino, 2002; Larrson et al., 2002; Castro et al., 2004).

ChEs are a class of serine hydrolases and generally classified into two isoenzymes: $\mathrm{AChE}$ and butyrylcholinesterase (BChE) also 
called pseudocholinesterase or non-specific ChE. Augustinsson (1949) first reported a high level of AChE activity in guppy muscle. Van der Wel and Welling (1989) demonstrated the contribution of BChE to total ChE activity was only about $1 \%$ in guppy. Garcia et al. (2000) also characterized ChE activities of guppy muscle and confirmed that AChE was the main ChE form in guppy muscle tissue. Interestingly, Castro et al. (2004) found that the guppy AChE activities were inhibited after $96 \mathrm{~h}$ in situ exposure in an acid mine drainage effluent, whereas mosquitofish AChE activities were not affected. This result suggests that guppy AChE is a sensitive biomarker to environmental pollutants.

The objective of this study was to examine the effects of shortterm exposure to NP on the ChE and carboxylesterase (CbE) activities of male guppies. Some environmental pollutants found to inhibit ChE activity may also inhibit CbE activity (Chanda et al., 2002). CbEs include several related isozymes widely distributed in living organisms. The physiological roles of these $\mathrm{CbEs}$ are still unclear but might be related to lipid metabolism and steroidogenesis (Jewell and Miller, 1998). Therefore, measurements of muscle $\mathrm{ChE}$, head $\mathrm{ChE}$, and liver $\mathrm{CbE}$ activities were simultaneously performed on male guppies exposed to $10,60,150$, or $300 \mu \mathrm{g} \mathrm{L}^{-1} \mathrm{NP}$ after $1,2,4$, or 7 days in the present study.

\section{Materials and methods}

\subsection{Chemicals and reagents}

NP (94\%) was obtained from Riedel-de Haën (Sigma-Aldrich, Germany). 3Aminobenzoic acid ethyl ester (MS222) and all other chemicals used in enzyme assay were obtained from Sigma Chemical Company (USA). Acetone (HPLC grade) was purchased from Mallinckrodt (Phillipsburg, USA). NP was dissolved in acetone for preparing the test stock solution.

\subsection{Animals and study design}

Adult male guppies were obtained from a local supplier and acclimated in the laboratory to a temperature of $28 \pm 2{ }^{\circ} \mathrm{C}$ and a 12 -h photoperiod for at least 7 days before the experiments. The guppies were fed daily with commercial dry flake food (TetraGuppy, Tetra, Germany). To eliminate the risk of leached potential endocrine disruptors, plastic materials were avoided in all aquaria and plumbing. Dechlorinated tap water was stored in a stainless-steel tank before use. The fish were exposed to either NP at nominal concentrations of $10,60,150$, or $300 \mu \mathrm{g} \mathrm{L}^{-1}$, or to acetone alone at a nominal concentration of $30 \mu \mathrm{g} \mathrm{L}^{-1}$ as solvent control for different exposure periods (1, 2, 4, or 7 days). Each group of five male guppies was kept in $5 \mathrm{~L}$ of water in a glass beaker. Each fish was fed an average of 3-4 mg of commercial dry flake food in each beaker just $30 \mathrm{~min}$ before daily test-water replacement. The test water was replaced every $24 \mathrm{~h}$ in all groups to maintain treatment concentrations. The fish were inspected daily for mortality and dead fish were immediately removed for the entire experimental period.

Based on the results of different time treatment experiments, 4-day treatments were repeated two more times at nominal concentrations of 150,300 , or $900 \mathrm{NP} \mu \mathrm{g} \mathrm{L}^{-1}$, or to acetone alone at a nominal concentration of $30 \mu \mathrm{g} \mathrm{L}^{-1}$ as solvent control to further examine effects of NP on muscle ChE of guppy and to estimate acute toxicity of NP for male guppies. For these two repeated 4-day treatment experiments, their experimental conditions followed the same experimental protocol as mentioned above. All Guppies exposed to $900 \mathrm{NP} \mu \mathrm{g} \mathrm{L}^{-1}$ died within 4 days; therefore, head and muscle $\mathrm{AChE}$ and liver $\mathrm{CbE}$ were only measured in fish exposed to 150 and $300 \mathrm{NP} \mu \mathrm{g} \mathrm{L}^{-1}$ from these two repeated 4-day treatment experiments.

\subsection{Tissue preparation}

After 1, 2, 4, or 7 days of treatment exposure, all fish were anesthetized in MS222 $\left(300 \mu \mathrm{g} \mathrm{L}^{-1}\right)$ for $15 \mathrm{~min}$. After whole-body weighing, the head was cut off just behind the operculum; sample of liver, testis, and muscle were removed for each guppy. Liver and testis wet weight were measured for each guppy. The gonadosomatic (GSI) and hepatosomatic (HSI) indices were calculated as the testis weight to fish whole-body weight and liver weight to fish whole-body weight, respectively. Muscle, head, and liver samples were stored at $-80{ }^{\circ} \mathrm{C}$ until biochemical assay within 1 week.

\subsection{ChE activity measurement}

Head or muscle samples were homogenized 1:10 (w/v) with $1 \mathrm{mM}$ EDTA and $0.5 \%$ Triton $\mathrm{X}-100$ in $0.1 \mathrm{M}$ phosphate buffer ( $\mathrm{pH} 7.5)$. The homogenates were centrifuged at $12,000 \mathrm{~g}$ for $20 \mathrm{~min}$ at $4{ }^{\circ} \mathrm{C}$ and $\mathrm{ChE}$ activity was immediately measured in the supernatant using the colorometric method of Ellman (Ellman et al., 1961). The reaction was triggered by adding $10 \mu \mathrm{L}$ of $75 \mathrm{mM}$ substrate (acetylthiocholine iodide for head and muscle samples and butyrylthiocholine iodide for muscle samples) to $990 \mu \mathrm{L}$ reaction mixture containing $50 \mu \mathrm{L}$ of $0.01 \mathrm{M}$ dithiobisnitrobenzoate (DTNB) and $50 \mu \mathrm{g}$ of muscle or head protein (for acetylthiocholine iodide) or $200 \mu \mathrm{g}$ of muscle protein (for butyrylthiocholine iodide) in $0.1 \mathrm{M}$ phosphate buffer ( $\mathrm{pH} 8.0$ ). The rate of increase of optical density of the reaction medium was measured using a Hitachi UV/VIS spectrophotometer at $412 \mathrm{~nm}$ for $60 \mathrm{~s}$ at room temperature. Because of limited muscle sample volumes, ChE activities were measured in duplicate. Despite selective inhibitors not being used, ChE activities using acetylthiocholine iodide as a substrate were referred as $\mathrm{AChE}$ and butyrylthiocholine iodide as a substrate were referred as BChE. The enzyme activity was expressed as $\mathrm{nmol} \mathrm{min}^{-1} \mathrm{mg}^{-1}$ of proteins.

\subsection{CbE activity measurement}

Livers were homogenized 1:10 with $0.2 \mathrm{mM}$ EDTA in $0.05 \mathrm{M}$ Tris- $\mathrm{HCl}$ buffer $(\mathrm{pH}$ 8.0) and centrifuged at $12,000 \mathrm{~g}$ for $20 \mathrm{~min}$ at $4^{\circ} \mathrm{C}$. The supernatant was immediately used for CbE activity measurement. CbE activity was determined with $p$-nitrophenyl acetate as substrate according to the method of Ljungquist and Augustinsson (1971). The reaction was triggered by adding $10 \mu \mathrm{L}$ of $0.05 \mathrm{M}$ p-nitrophenyl acetate (in ethanol) to $1 \mathrm{~mL}$ reaction mixture containing $50 \mu \mathrm{g}$ liver proteins in $0.05 \mathrm{M}$ Tris- $\mathrm{HCl}$ buffer $(\mathrm{pH} 8.0)$. The rate of increase of optical density of the reaction medium was measured using a Hitachi UV/VIS spectrophotometer at $405 \mathrm{~nm}$ for $60 \mathrm{~s}$ at room temperature. The $\mathrm{CbE}$ activities were measured in duplicate. The enzyme activity was calculated as $\mathrm{nmol} \mathrm{min}{ }^{-1} \mathrm{mg}^{-1}$ of proteins.

\subsection{Protein determination}

The protein concentrations of the head, muscle or liver samples were measured using Bradford's method (Bradford, 1976), with bovine serum albumin as the standard. All protein measurements were performed in triplicate.

\subsection{Statistical analysis}

The acute toxicity of NP for male guppy was determined from daily mortality noted from different treatment experiments with concentrations ranging from 10 to $900 \mu \mathrm{g} \mathrm{L}^{-1}$. The nominal concentrations lethal to $50 \%$ of the organisms ( $\mathrm{LC}_{50}$ ) for $\mathrm{NP}$ at $96 \mathrm{~h}$ were calculated using trimmed Spearman-Karber analysis with trimmed Spearman-Karber Program (version 1.5) obtained from Environmental Monitoring Systems Laboratory (USEPA, Cincinnati, Ohio).

For comparison reasons, data were expressed as ratio of change from the respective control value (taken as $100 \%$ ) for $\mathrm{ChE}$ or $\mathrm{CbE}$ activities from different time treatments. No statistical test was conducted in these data because of limited sample sizes and only graphical expression was presented for these different time treatment experiments.

For the 4-day treatment experiments, three independent experiments were conducted. Differences among treatment groups were analyzed by the nonparametric Kruskal-Wallis test using the Minitab statistical program (Version 13.2). If a significant result was found, Mann-Whitney $U$ test was used to determine which treatment groups were significantly different from the controls. Differences were considered significant if $P<0.05$.

\section{Results}

\subsection{General biological parameters from different time treatments}

Two, one, and five fish died in 10,150 , and $300 \mu \mathrm{g} \mathrm{L}^{-1}$ of NP during 7 days of exposure, respectively (Table 1 ). Therefore, there were only three NP treatment groups in the 7-day exposure experiment. There were no general dose-related trends in the body weight, GSI index or HSI index among different NP-treated guppies after $1,2,4$, or 7 days of exposure. 
Table 1

Body weight, GSI, and HSI (mean \pm SD) in male guppies exposed to NP after 1, 2, 4, or 7 day of treatment

\begin{tabular}{llllll}
\hline Exposure & $\begin{array}{l}\text { NP treatment } \\
\left(\mu \mathrm{g} \mathrm{L}^{-1}\right)\end{array}$ & $n$ & $\begin{array}{l}\text { Body weight } \\
(\mathrm{g})\end{array}$ & GSI $(\%)$ & HSI (\%) \\
\hline 1 day & Control & 5 & $0.27 \pm 0.08$ & $2.89 \pm 0.41$ & $1.12 \pm 0.28$ \\
& 10 & 5 & $0.31 \pm 0.08$ & $1.67 \pm 0.44$ & $1.24 \pm 0.55$ \\
& 60 & 5 & $0.37 \pm 0.14$ & $2.09 \pm 0.74$ & $1.00 \pm 0.44$ \\
& 150 & 5 & $0.21 \pm 0.08$ & $2.34 \pm 0.63$ & $1.67 \pm 0.35$ \\
& 300 & 5 & $0.27 \pm 0.08$ & $2.85 \pm 0.75$ & $1.39 \pm 0.31$ \\
& & & & & \\
days & Control & 5 & $0.31 \pm 0.12$ & $1.35 \pm 0.45$ & $1.03 \pm 0.42$ \\
& 10 & 5 & $0.31 \pm 0.04$ & $2.93 \pm 1.83$ & $1.11 \pm 0.61$ \\
& 60 & 5 & $0.29 \pm 0.03$ & $2.15 \pm 0.89$ & $1.48 \pm 0.79$ \\
& 150 & 5 & $0.27 \pm 0.08$ & $2.16 \pm 0.67$ & $1.58 \pm 0.74$ \\
& 300 & 4 & $0.34 \pm 0.10$ & $1.93 \pm 0.59$ & $1.40 \pm 0.57$ \\
4 days & Control & 5 & $0.34 \pm 0.09$ & $2.68 \pm 0.52$ & $1.24 \pm 0.91$ \\
& 10 & 5 & $0.30 \pm 0.10$ & $3.09 \pm 0.98$ & $1.34 \pm 0.27$ \\
& 60 & 5 & $0.27 \pm 0.08$ & $2.65 \pm 0.88$ & $1.75 \pm 0.48$ \\
& 150 & 5 & $0.28 \pm 0.06$ & $2.49 \pm 0.46$ & $1.23 \pm 0.33$ \\
& 300 & 4 & $0.30 \pm 0.05$ & $2.85 \pm 0.91$ & $2.18 \pm 0.95$ \\
& & & & & \\
7 days & Control & 5 & $0.32 \pm 0.08$ & $2.80 \pm 1.09$ & $1.67 \pm 0.70$ \\
& 10 & 3 & $0.27 \pm 0.08$ & $2.99 \pm 0.72$ & $2.92 \pm 0.19$ \\
& 60 & 5 & $0.32 \pm 0.06$ & $2.09 \pm 0.99$ & $2.56 \pm 0.90$ \\
& 150 & 4 & $0.28 \pm 0.06$ & $1.64 \pm 0.63$ & $2.32 \pm 0.73$ \\
& 300 & 0 & All guppies died within & 6 days \\
& & & & &
\end{tabular}

\subsection{Effects of NP on ChE and CbE activities from different time treatments}

Muscle AChE inhibition of male guppies decreased by about $30-40 \%$ in all NP treatment groups after 4-day exposure, and 60 and $150 \mu \mathrm{g} \mathrm{L}^{-1}$ of NP treatment groups after 7-day exposure (Fig. 1A). On the other hand, there were no obvious changes in inhibition of BChE in the muscle of male guppy for any NP treatments in different exposure times (data not shown). In addition, a large variation and no clear trend in the head AChE activities of male guppies was noted in different NP treatment groups from different time exposures (Fig. 1B). There were no differences in the liver $\mathrm{CbE}$ activities of male guppies among different NP treatment groups after 1, 2, or 4 days of treatment (Fig. 1C); however, roughly $40 \%$ increase of liver $\mathrm{CbE}$ activities was found in the 10,60 , and $150 \mu \mathrm{g} \mathrm{L}^{-1}$ of NP treatment groups after 7-day exposure.

\subsection{Effects of NP on male guppies after 4 days of exposure}

Among three independent 4-day treatment experiments, one fish died in $300 \mu \mathrm{g} \mathrm{L}^{-1}$ of NP during 4 days of exposure (Table 2). There were no significant changes in GSI and HSI index in guppies exposed to150 or $300 \mu \mathrm{g} \mathrm{L}^{-1}$ compared to the control (Table 2). There was statistically significant inhibition of muscle AChE activities after 4-day exposure in 150 or $300 \mu \mathrm{g} \mathrm{L}^{-1}$ (Fig. 2A). The muscle AChE inhibition in male guppies were about $73 \%$ and $65 \%$ of muscle AChE in respective controls for 150 and $300 \mu \mathrm{g} \mathrm{L}^{-1}$ respectively. On the other hand, there were no head $\mathrm{ChE}$ and liver $\mathrm{CbE}$ activities differences in male guppies exposed to 150 or $300 \mu \mathrm{g} \mathrm{L}^{-1}$ compared to control (Fig. 2B \& C). Based on limited mortality data in this study, the 96-h NP $\mathrm{LC}_{50}$ value for male guppy was estimated to be $475 \mu \mathrm{g} \mathrm{L}^{-1}$ with $95 \%$ confidence interval of $401-563 \mu \mathrm{g} \mathrm{L}^{-1}$.

\section{Discussion}

A decreased GSI can be used as an indicator of gonadal dysfunction in fish after estrogenic exposure (Kim, 1999). In
A

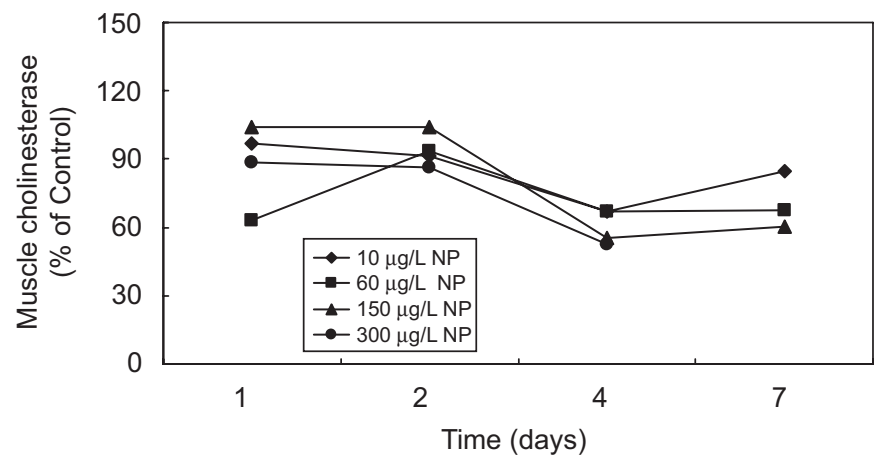

B

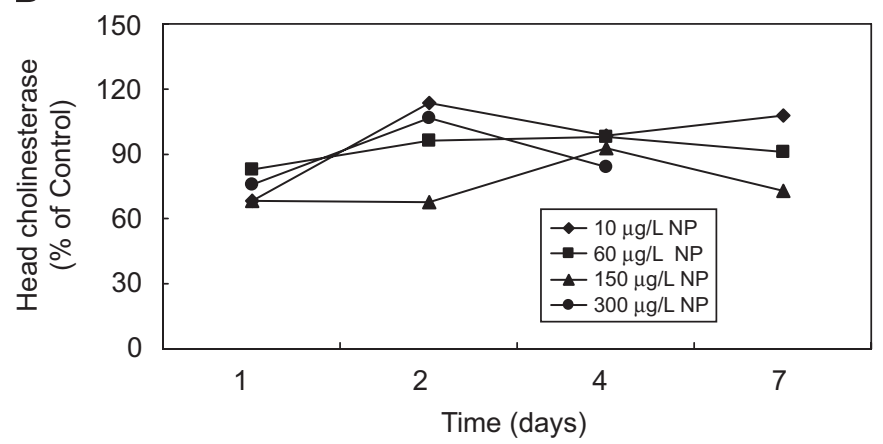

C

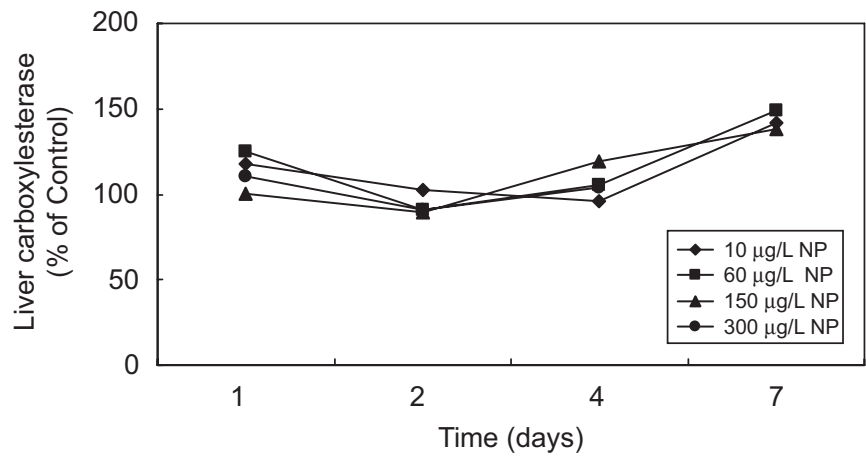

Fig. 1. Effects of NP on (A) muscle AChE , (B) head AChE, (C) liver CbE activities (mean $\pm S D$ ) in male guppies after1, 2, 4, or 7 days of treatment. The sample size of each treatment group was referred to Table 1 .

Table 2

Body weight, GSI, and HSI (mean \pm SD) in male guppies exposed to NP after 4 days of treatment from three independent experiments

\begin{tabular}{lllll}
\hline NP treatment $\left(\mu \mathrm{g} \mathrm{L}^{-1}\right)$ & $n$ & Body weight $(\mathrm{g})$ & GSI (\%) & HSI (\%) \\
\hline Control & 15 & $0.21 \pm 0.09$ & $2.76 \pm 0.88$ & $1.72 \pm 0.83$ \\
150 & 15 & $0.23 \pm 0.08$ & $2.11 \pm 1.03$ & $1.70 \pm 0.65$ \\
300 & 14 & $0.22 \pm 0.07$ & $2.26 \pm 1.25$ & $2.15 \pm 0.84$ \\
\hline
\end{tabular}

addition, an increased HSI is expected from vitellogenin induction resulting from enhanced liver metabolism, leading to an enlarged live in fish after estrogenic exposure (Li and Wang, 2005). Therefore, increased HSI or decreased GSI might be expected in fish after NP exposure. In this study, no significant changes were found in the GSI and HSI of male guppies after 4 days of NP treatment. This is probably due to a high degree of individual variation within each treatment group and a short-term exposure used in this study. 
A

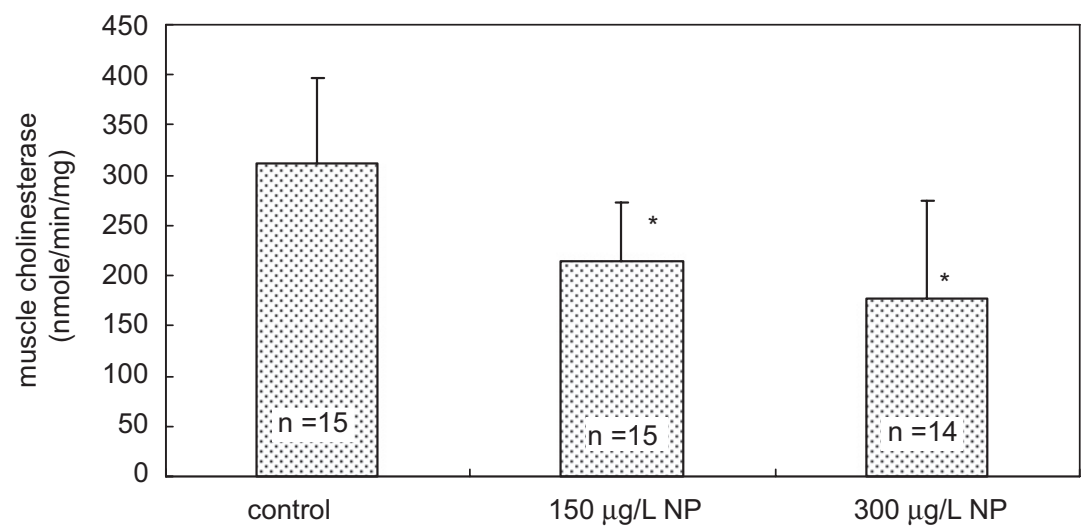

B

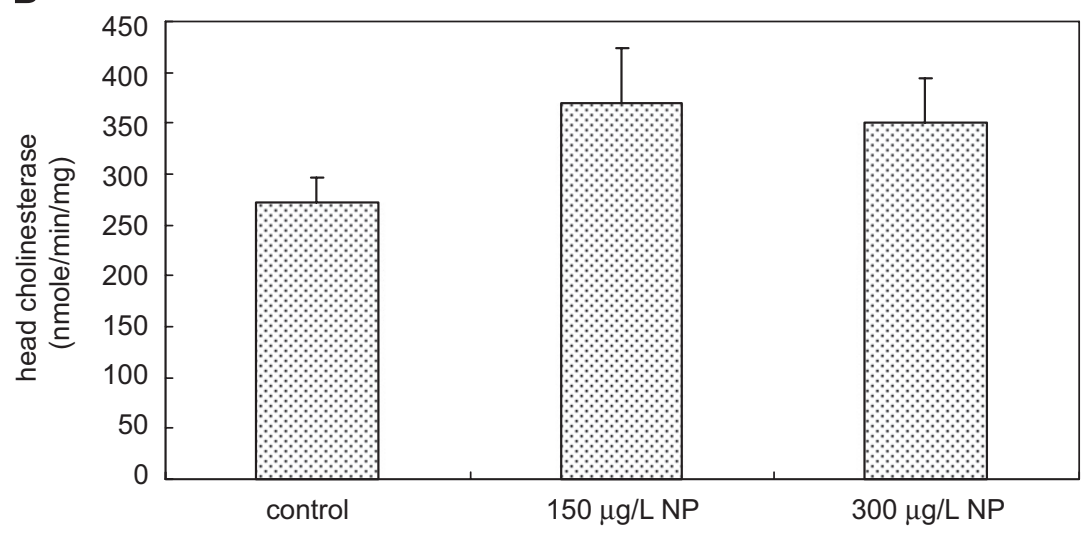

C

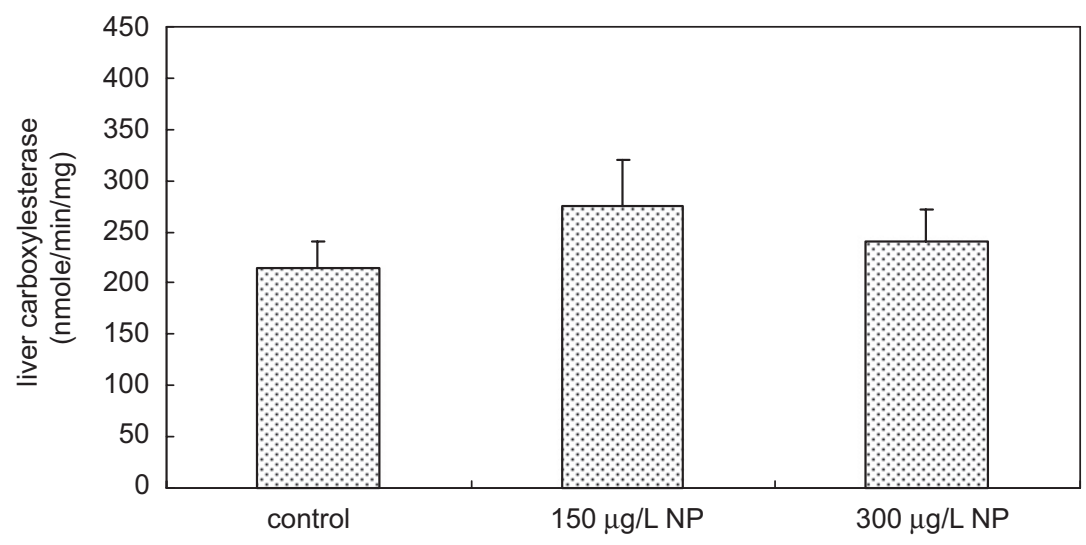

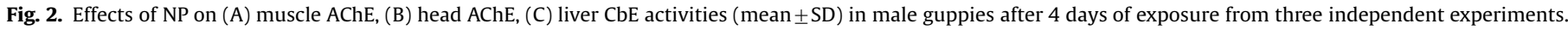
An asterisk denotes a significant difference from the controls at $P<0.05$.

There is general agreement ChE inhibition can be used as a useful biomarker for exposure to OP and carbamate pesticides in vivo (Fulton and Key, 2001). However, several studies published in the past decade have demonstrated the possible effects of ionic surfactants on ChE activity (Guilhermino et al., 1998, 2000; Stock et al., 2004). Interestingly, this study also found a nonionic surfactant, NP, could inhibit ChE activity in male guppy at or above $150 \mu \mathrm{g} \mathrm{L}^{-1}$ of NP treatment groups having 4- or 7-day exposure. Freshwater concentrations of NP have been reported to be in the range of $<0.01-180 \mu \mathrm{g} \mathrm{L}^{-1}$, with average NP concentrations less than $10 \mu \mathrm{g} \mathrm{L}^{-1}$ in surface water (Bennie, 1999). In this study, the concentrations of NP causing ChE inhibition in fish are at the high end of NP concentration range occurring in the aquatic environ- ment. This information may imply negligible acute cholinergic effects on aquatic animals exposed to NP in the aquatic environment. However, it should not ignore potential toxic effects by ChE inhibition on aquatic animals in some accidental NP spills or highly NP-polluted aquatic environment. More studies should be conducted to examine the exposure of NP on the ChE inhibition of different aquatic animals.

There is conflicting evidence concerning the responsiveness of different tissues to ChE inhibition in aquatic animals. Although most studies focused on the relationship between brain ChE inhibition and acute toxicity, it has been pointed out that fish ChE inhibition in the muscle is a better predictor of acute lethality than in the brain (Perkins and Schlenk, 2000; Fulton and Key, 
2001; El-Alfy et al., 2001). In this study, the inhibition of AChE in the muscle (up to $65 \%$ of control) was much lower than in the head (up to $87 \%$ of control) for male guppies exposed to $300 \mu \mathrm{g} \mathrm{L}^{-1}$ of NP after a 4-day treatment with a 96-h NP $\mathrm{LC}_{50}$ value of $475 \mu \mathrm{g} \mathrm{L}^{-1}$. This result also confirmed that ChE inhibition in the muscle was a better predictor of acute lethality than in the head. In fact, some studies showed muscle ChE inhibition was more sensitive to OPs and/or carbamates than brain ChE inhibition (Sturm et al., 1999, 2000; Whitehead et al., 2005). Interestingly, Payne et al. (1996) reported that significant reductions of ChE activities were found in the muscle tissues but not in the brain tissues of fish from field trial studies. In this study, a significant decrease in AChE inhibition was also only noted in the muscle tissues but not in the head tissues of male guppies exposed to 150 or $300 \mu \mathrm{g} \mathrm{L}^{-1}$. The responsiveness of different tissues to ChE inhibition may involve various factors such as absorption, metabolism, elimination, physiology, sex, and types of ChE inhibitors and may be species specific (Carr et al., 1997; Perkins and Schlenk, 2000; El-Alfy et al., 2001).

In general, OP-induced $\mathrm{CbE}$ inhibition is less sensitive than OPinduced ChE inhibition (Ehrich and Correll, 1998). CbEs have been shown to detoxify various ester-containing environmental contaminants (i.e. carbamates, Ops, and pyrethroids), and can play a protective role against the acute toxicity of OP compounds (Cashman et al., 1996). It has suggested that OPs are potent inhibitors of CbEs in mammals (Cashman et al., 1996), whereas peroxisome proliferators which include a diverse group of compounds (i.e. hypolipidemic drugs, halogenated solvents, and industrial plasticizers) can induce CbEs (Moody et al., 1992). In this study, there were no statistically significant changes of liver $\mathrm{CbE}$ in male guppies for any NP treatments after a 4-day exposure. However, there was increase of liver CbE (40\% increase) in male guppies exposed to $150 \mu \mathrm{g} \mathrm{L}^{-1}$ after 7 days of treatment. It will be interesting to further explore any effects of NP on $\mathrm{CbE}$ activities at higher NP exposure concentrations using other fish species.

The chemical structure of NP lacks the molecular interaction potential of the ester group to bind on the catalytic site of ChEs or CbEs; therefore, it is not surprising that no inhibition of liver $\mathrm{CbE}$ was noted in male guppy exposed to NP. On the other hand, it is very interesting and unexpected to find muscle AChE inhibition in 4- and 7-day NP treated guppies. Although there is no published information regarding ChE inhibition being caused by NP in fish, the nonionic surfactant property of NP might change ChE activity by binding to the anionic site of the enzyme, by modifying the enzyme solubility because of membrane disruption or by changing allosteric interaction of the enzyme structure (Cserháti, 1995). Further, Talorete et al. (2001) have suggested two possible mechanisms for how alkylphenolic compounds might inhibit AChE activities based on their in vitro results on PC12 cells. One mechanism is, alkylphenols act as antagonists by competing with the nerve growth factor for their binding sites on plasma membranes; the other is, these chemicals suppress protein kinase activity by changing the signal transduction pathway of the receptor tyrosine kinase by blocking autophosphorylation. More detailed studies will be conducted to clarify the direct or indirect mechanism of NP to alter or regulate ChE activities in vivo.

\section{Conclusion}

To the best of my knowledge, this is the first report showing ChE activity inhibition by NP in fish. This result also supports the hypothesis that diverse classes of environmental pollutants can inhibit ChE activity in various organisms. Further mechanistic studies are needed to define how NP can directly or indirectly alter ChE activities at molecular level. NP is a ubiquitous environmental pollutant in the aquatic environment; therefore, the implication of ChE inhibition of NP on potential impacts of aquatic animals also warrants further research in vivo.

\section{Acknowledgments}

This study was supported by the National Science Council under Grant NSC 95-2313-B-002-102. The author thanks Ms. YuWen Chen for her assistance in enzyme activity measurements and Mr. Cheng-Ching Wang for his assistance on animal maintenance.

\section{References}

Araújo, C.V., Cohin-de-Pinho, S.J., da S Santos, J., Delgado, F., Santana, L.C., Chastinet, C.B., da Silva, E.M., 2006. In situ and laboratory bioassays using Poecilia reticulata peters, 1859 in the biomonitoring of an acidic lake at Camaç ari, BA, Brazil. Chemosphere 65, 599-603.

Augustinsson, K.B., 1949. Substrate concentration and specificity choline estersplitting enzymes. Arch. Biochem. Biophys. 23, 111-126.

Bandiera, S.M., 2006. Reproductive and endocrine effects of $p$-nonylphenol and methoxychlor: a review. Immun. Endocr. Metab. Agents Med. Chem. 6, 15-26.

Bennie, D.T., 1999. Review of the environmental occurrence of alkylphenols and alkylphenol ethoxylates. Water Qual. Res. J. Canada 34, 79-122.

Bradford, M.M., 1976. A rapid and sensitive method for the quantitation of microgram quantities of protein utilizing the principle of protein-dye binding. Anal. Biochem. 72, 248-254

Carr, R.L., Ho, L.L., Chambers, J.E., 1997. Selective toxicity of chlorpyrifos to several species of fish during an environmental exposure: biochemical mechanisms. Environ. Toxicol. Chem. 16, 2369-2374.

Cashman, J.R., Perotti, B.Y., Berkman, C.E., Lin, J., 1996. Pharmacokinetics and molecular detoxication. Environ. Health Perspect. 104S, 23-40.

Castro, B.B., Sobral, O., Guilhermino, L., Ribeiro, R., 2004. An in situ bioassay integrating individual and biochemical responses using small fish species. Ecotoxicology 13, 667-681.

Chanda, S.M., Lassiter, T.L., Moser, V.V., Barone Jr., S., Padilla, S., 2002. Tissue carboxylesterases and chlorpyrifos toxicity in the developing rat. Hum. Ecol. Risk Assess. 8, 75-90.

Cserháti, T., 1995. Alkyl ethoxylated and alkyphenol ethoxylated nonionic surfactants interaction with bioactive compounds and biological effects. Environ. Health Perspect. 103, 358-364.

Ehrich, M., Correll, L., 1998. Inhibition of carboxylesterases in SH-SY5Y human and NB41A3 mouse neuroblastoma cells by organophosphorus esters. J. Toxicol. Environ. Health 53, 385-399.

El-Alfy, A., Grisle, S., Schlenk, D., 2001. Characterization of salinity-enhanced toxicity of aldicarb to Japanese medaka: sexual and developmental differences. Environ. Toxicol. Chem. 20, 2093-2098.

Ellman, G., Courtney, D.K., Andres Jr., .V., Featherstone, R.M., 1961. A new and rapid colorimetric determination of acetylcholinesterase activity. Biochem. Pharmacol. 7, 88-95.

Frasco, M.F., Guilhermino, L., 2002. Effects of dimethoate and beta-naphthoflavone on selected biomarkers of Poecilia reticulate. Fish Physiol. Biochem. 26, 149-156.

Fulton, M.H., Key, P.B., 2001. Acetylcholinesterase inhibition in estuarine fish and invertebrates as an indicator of organophosphorus insecticide exposure and effects. Environ. Toxicol. Chem. 20, 37-45.

Garcia, L.M., Castro, B., Ribeiro, R., Guilhermino, L., 2000. Characterization of cholinesterase from guppy (Poecilia reticulata) muscle and its in vitro inhibition by environmental contaminants. Biomarker 5, 274-284.

Guilhermino, L., Barros, P., Silva, M., Soares, A.M., 1998. Should the use of inhibition of cholinesterases as a specific biomarker for organophosphate and carbamate pesticides be questioned? Biomarker 3, 157-163.

Guilhermino, L., Lacerda, M.N., Nogueira, A.J., Soares, A.M., 2000. In vitro and in vivo inhibition of Daphnia magna acetylcholinesterase by surfactant agents: possible implications for contamination biomonitoring. Sci. Total Environ. 247, 137-141.

Jewell, W.T., Miller, M.G., 1998. Identification of a carboxylesterase as the major protein bound by molinate. Toxicol. Appl. Pharmacol. 149, 226-234.

Jones, S.B., King, L.B., Sappington, L.C., Dwyer, F.J., Ellersieck, M., Buckler, D.R., 1998. Effects of carbaryl, permethrin, 4-nonylphenol, and copper on muscarinic cholinergic receptors in brain of surrogate and listed fish species. Comp. Biochem. Physiol. 120C, 405-414.

Khan, S.Z., Kirk, C.J., Michelangeli, F., 2003. Alkylphenol endocrine disrupters inhibit $\mathrm{IP}_{3}$-sensitive $\mathrm{Ca}^{2+}$ channels. Biochem. Biophys. Res. Commun. 310, 261-266.

Kim, D.E., 1999. A strategy for assessing the effects of xenobiotics on fish reproduction. Sci. Total Environ. 225, 3-11.

Larsson, D.G., Kinnberg, K., Sturve, J., Stephensen, E., Skön, M., Förlin, L., 2002. Studies of masculinization, detoxification, and oxidative stress responses in 
guppies (Poecilia reticulata) exposed to effluent from a pulp mill. Ecotoxicol. Environ. Saf. 52, 13-20.

Lee, S.-B., Choi, J., 2006. Multilevel evaluation of nonylphenol toxicity in fourthinstar larvae of Chironomus riparius (Diptera, Chironomidae). Environ. Toxicol. Chem. 25, 3006-3014

Li, M.-H., 2008. Effects of nonionic and ionic surfactants on survival, oxidative stress, and cholinesterase activity of planarian. Chemosphere 70, 1796-1803.

Li, M.-H., Wang, Z.-R., 2005. Effect of nonylphenol on plasma vitellogenin of male adult guppies (Poecilia reticulata). Environ. Toxicol. 20, 53-59.

Ljungquist, A., Augustinsson, K.B., 1971. Purification and properties of two carboxylesterases from rat-liver microsomes. Eur. J. Biochem. 23, 303-313.

Lussier, S.M., Champlin, D., LiVolsi, J., Poucher, S., Pruell, R.J., 2000. Acute toxicity of para-nonylphenol to saltwater animals. Environ. Toxicol. Chem. 19, 617-621.

Nimrod, A.C., Benson, W.H., 1996. Environmental estrogenic effects of alkyphenol ethoxylates. Crit. Rev. Toxicol. 26, 335-364.

Moody, D.E., Gibson, G.G., Grant, D.F., Magdalou, J., Rao, M.S., 1992. Peroxisome proliferators, a unique set of drug-metabolizing enzyme inducers: commentary on a symposium. Drug Metab. Dispos. 20, 779-791.

Payne, J.F., Mathieu, A., Melvin, W., Fancey, L.L., 1996. Acetylcholinesterase, an old biomarker with a new future? Field trials in association with two urban rivers and a paper mill in Newfoundland. Mar. Pollut. Bull. 32, 225-231.

Perkins Jr., E.J., Schlenk, D., 2000. In vivo acetylcholinesterase inhibition, metabolism, and toxicokinetics of aldicarb in channel catfish: role of biotransformation in acute toxicity. Toxicol. Sci. 53, 308-315.

Pierson, K.B., 1981. Effects of chronic zinc exposure on the growth, sexual maturity, reproduction, and bioaccumulation of the guppy, Poecilia reticulate. Can. J. Fish Aquat. Sci. 38, 23-31.
Soreq, H., Seidman, S., 2001. Acetylcholinesterase-new roles for an old actor. Nat Rev. Neurosci. 2, 294-302.

Staples, C., Mihaich, E., Carbone, J., Woodburn, K., Klecka, G., 2004. A weight of evidence analysis of the chronic ecotoxicity of nonylphenol ethoxylates, nonylphenol ether carboxylates, and nonylphenol. Hum. Ecol. Risk Assess. 10 999-1017.

Stock, F., Hoffmann, J., Ranke, J., Störmann, R., Ondruschka, B., Jastorff, B., 2004 Effects of ionic liquids on the acetylcholinesterase-a structure-activity relationship consideration. Green Chem. 6, 286-290.

Sturm, A., da Silva de Assis, H.C., Hansen, P.D., 1999. Cholinesterases of marine teleost fish: enzymological characterization and potential use in the monitoring of neurotoxic contamination. Mar. Environ. Res. 47, 389-398.

Sturm, A., Wogram, J., Segner, H., Liess, M., 2000. Different sensitivity to organophosphates of acetylcholinesterase and butyrylcholinesterase from three-spined stickleback (Gasterosteus aculeatus): application in biomonitoring. Environ. Toxicol. Chem. 19, 1607-1615.

Talorete, T.P.N., Isoda, H., Maekawa, T., 2001. Alkylphenolic compounds and their effect on the injury rate, survival and acetylcholinesterase activity of the rat neuronal cell line PC12. Cytotechnology 36, 163-169.

van der Wel, H., Welling, W., 1989. Inhibition of acetylcholinesterase in guppies (Poecilia reticulata) by chlorpyrifos at sublethal concentrations: methodological aspects. Ecotoxicol. Environ. Saf. 17, 205-215.

Whitehead, A., Anderson, S.L., Ramirez, A., Wilson, B.W., 2005. Cholinesterases in aquatic biomonitoring: assay optimization and species-specific characterization for a California native fish. Ecotoxicology 14, 597-606.

Ying, G.G., Williams, B., Kookana, R., 2002. Environmental fate of alkylphenols and alkylphenol ethoxylates-a review. Environ. Int. 28, 215-226. 